\title{
MBEMBE, ACHILle. SAIR DA GRANDE NoItE: ENSAIO SOBRE a ÁFrICA DESCOLONIZADA ${ }^{1}$
}

\author{
Diego dos Santos Reis ${ }^{2}$
}

Nós nos pusemos de pé e agora avançamos.

Quem será capaz de nos fazer voltar à servidão?

Frantz Fanon, L’An $V$ de la Révolution Algérienne.

MBEMBE, Achille. Sair da Grande Noite: ensaio sobre a África descolonizada. Trad. Fábio Ribeiro. Petrópolis, RJ: Vozes, 2019a.

Quarto livro publicado da Coleção África e os Africanos, da Editora Vozes, Sair da Grande Noite: Ensaio sobre a África descolonizada, de Achille Mbembe, é um ensaio vigoroso, escrito para perturbar ordens legitimadas e histórias políticas do continente africano, narradas desde a perspectiva europeia. A obra, que agora se apresenta ao/à leitor/a brasileiro/a, foi publicada em língua francesa, em 2010, pelas Éditions La Découverte, mesma editora que, recentemente, lançou o último livro escrito pelo filósofo e cientista político, Brutalisme (MBEMBE, 2020).

O título, tomado de empréstimo a Frantz Fanon (2003), remete à prometeica expressão do psiquiatra martinicano, quando este evoca a saída da "grande noite", na qual os sujeitos colonizados foram mergulhados, e a

\footnotetext{
${ }^{1}$ Tradução de Fábio Ribeiro. Petrópolis, RJ: Vozes, 2019. 256 p.

2 Professor Adjunto da Universidade Federal da Paraíba (UFPB), João Pessoa, PB - Brasil e Professor Colaborador do Programa de Pós-Graduação em Humanidades, Direitos e Outras Legitimidades (Diversitas/FFLCH/USP), São Paulo, SP - Brasil. Coordenador do Travessias - Grupo de Pesquisa em Filosofia, Educação e Decolonialidade (UFPB/CNPq). ') https://orcid.org/0000-0001-6977-7166. E-mail: diegoreis.br@gmail.com.
}

${ }^{3}$ A editora n-1 publicará, em breve, a tradução brasileira do livro.

https://doi.org/10.1590/0101-3173.2022.v45esp.22.p455

\section{(6)}

This is an open-access article distributed under the terms of the Creative Commons Attribution License. 
necessidade de abandonar "[...] essa Europa que não para de falar no homem, ao mesmo tempo que o massacra onde quer que o encontre, em todas as esquinas de suas ruas limpas, em todas as esquinas do mundo." (FANON, 2003, p. 301).

Mas se engana quem pensa que, em Sair da Grande Noite, o ensaísta, pesquisador e professor camaronês de história e ciência política, cujos trabalhos têm alcançado notoriedade, nos últimos anos, com aumento expressivo das traduçôes em línguas estrangeiras, busca apenas reconstruir os processos históricos em torno dos movimentos de descolonização dos países africanos e avaliá-los politicamente. Como afirma Mbembe (2019a, p. 11), logo de saída em seu ensaio, não se trata de realizar um balanço das independências, porém, antes, de examinar como "[...] a descolonização inaugurou o tempo da bifurcação na direção de futuros inumeráveis.”

$\mathrm{O}$ argumento central do livro baseia-se na reflexão sobre a descolonização, entendida como experiência de emergência e de revolta. Mas náo apenas isso. No rastro das lutas de independência e das batalhas anticoloniais do século XX, indaga-se sobre o dia seguinte da comunidade descolonizada, cuja concretização tornaria possível a "[...] manifestação de um poder próprio de gênese", a um só tempo, "[...] articulação de uma diferença e de uma força positiva" (MBEMBE, 2019a, p. 10) e experimentação e criação de um mundo novo, nos antípodas da modernidade ocidental.

O sonho, contudo, parece chocar-se com as realidades singulares das nações libertas e com as práticas de governos pós-coloniais, que culminam por reproduzir estruturas econômicas e formas sociais herdadas da colonização. Daí a tarefa do ensaísta de revisitar os horizontes e as realizaçóes dos movimentos de descolonização, para retomar a exigência de criação de novas imagens do pensamento, de rupturas anunciadas e da promessa engendrada na emersão do mergulho na "grande noite": a revolução impossivel.

$\mathrm{O}$ apelo à revoluçấo e à vontade de vida, no continente africano, evidencia, de outro lado, a presença de duas vozes que acompanham o exercício político de Mbembe: a de Frantz Fanon e a de Jean-Marc Ela. Vozes que se inscrevem no texto, em linha dupla, como interlocuçóes fundamentais para o pensador, não apenas no presente ensaio, mas ao longo de sua trajetória acadêmica. Jean-Marc Ela, sociólogo e teólogo camaronês, falecido em 2008, une-se a Fanon, esses "dois pensadores do devir ilimitado", como caracteriza Mbembe, à memória dos quais o livro é dedicado. Ambos os intelectuais, em 
sua militância, não deixaram de apontar os privilégios epistêmicos, políticos e ontológicos conferidos àqueles que se localizam na zona do ser (FANON, 2008), além da importância de expandir a descolonização à epistemologia, subvertendo a relação entre sujeitos e objetos do conhecimento (ELA, 2013). Relação essa, aliás, que Mbembe (2017) problematizaria em outros trabalhos, ao discutir autodeterminação, autogoverno, humanismo e vida colonizada.

Nas trilhas de Necropolítica, Crítica da Razão Negra e Politicas da Inimizade, o desarranjo provocado pelo livro merece destaque. A força rítmica do texto, sua forma serpenteante e as imagens em profusão parecem apontar para a necessidade de tensionar a escrita política, como laboratório de experimentação de modos de enunciação atravessados pela inscrição do próprio corpo no corpo do texto, no limiar entre o teórico e o poético. $\mathrm{O}$ ensaio não só embaralha fronteiras entre vozes narrativas, registros e referências, como esboroa as divisas entre gêneros, inscrevendo a memória, suas operaçóes e seus suportes na cena do texto. Não estranha, assim, que Mbembe adote no início do ensaio um registro narrativo autobiográfico, irônico, por vezes, ao denunciar o tempo "fora dos eixos", "a partir do crânio de um morto", como Hamlet (SHAKESPEARE, 2015). Tal como o encontro do príncipe dinamarquês com Yorick, o bobo da corte, o contraste entre as memórias da infância e a visão de seus restos mortais configura-se como memento mori, meditação diante do espectro que assombra o autor: o colonialismo.

Espectros plurais, coloniais e contracoloniais, os quais se multiplicam ao longo do texto e digladiam sob os olhos do/a leitor/a, na disputa de narrativas e nas negociações envolvidas na escrita da história. Não é à toa que as imagens e visóes de tumbas, ossadas, cadáveres e lápides se fazem presentes, em todos os capítulos. Às vezes, explicitamente nomeadas; noutras, soterradas por camadas espessas de narrativas históricas, destroços de guerras sangrentas e lutas armadas contra metrópoles coloniais.

Outra voz, sub-reptícia, mas loquaz, parece ressoar também do mundo dos mortos: a de Aimé Césaire e seu Discurso sobre o colonialismo. A denúncia de um mundo de falsificaçóes e de amplas reservas de imaginários falaciosos desvela o solo das representaçóes e símbolos cruciais para manutenção do projeto colonial. Como expóe o poeta do Movimento Negritude, a eloquência da prosa colonial humanista mascara o racismo, o ódio e o desprezo pelos colonizados, forças motrizes da necropolítica que incide ostensivamente sobre corpos designados como racialmente inferiores. Entretanto, ressoa também o Césaire (2010, p. 113) do Discurso sobre a negritude, quando, 
diante do recrudescimento do racismo no mundo inteiro, pergunta-se o poeta martinicano se seria "[...] o momento de baixarmos a guarda e nos desarmarmos", sem esquecer que negro é sinônimo "[...] de luta tenaz pela liberdade e de [indômita] esperança." (CÉSAIRE, 2010, p. 108). De fato, não é possível dissociar a violência colonial da violência racial, com sua pulsão genocida, que aniquila subjetividades e imprime sobre os corpos a marca da raça como signo de morte, em um sistema de subjugação e extermínio.

Se as lutas anticoloniais culminaram com a conquista da independência e com a liberdade do jugo colonial, as heranças nefastas, porém, não deixaram de estruturar as instituiçóes, os ordenamentos e as agências dos Estados independentes, como último gesto do terror colonial. Entre fantasmas e simulacros, questiona-se o autor:

[...] nós éramos então descolonizados, mas será que por isso éramos livres? A independência sem liberdade, a liberdade incessantemente adiada, a autonomia na tirania - era essa, como descobri mais tarde, a assinatura própria da pós-colônia, o verdadeiro legado da farsa que foi a colonização. (MBEMBE, 2019a, p. 44).

Tragédia ou farsa, tragédia $e$ farsa, os legados do autoritarismo, da violência e da destruição materializaram-se por todo o continente africano, em leis draconianas, estados de emergência e terra arrasada. Daí a "potência do simulacro", de que fala Mbembe, remeter tanto à "independência sem liberdade" quanto à atitude dos países colonizadores, na recusa ao sepultamento e à escuta dos fantasmas coloniais, os quais exigem políticas de justiça, verdade e reparação. No cruzamento do espírito, da matéria e dos mundos, a permanência da colonialidade adquire outras faces - do encarceramento massivo dos sujeitos racializados ao genocídio da juventude negra, que, na diáspora, reconstituem projetos políticos de Estado (REIS, 2020a). Fato é que, em um mundo dividido hierarquicamente, "[...] a ideia de uma condição humana comum continua longe de ser admitida na prática, diversas formas de apartheid, de exclusão, de destituições estruturais substituíram as antigas divisôes propriamente coloniais." (MBEMBE, 2018, p. 279).

É aí que reaparece também o tema das fronteiras, constante nos trabalhos do autor, na medida em que "[...] o arquivo ocidental está baseado na cristalização da ideia de fronteira.” (MBEMBE, 2019b, s.p.). A expansão das fronteiras, como balizas coloniais que demarcam aqueles que estão dentro e os que estão de fora, evidencia, assim, o desejo de reforço de dinâmicas 
segregacionistas (REIS, 2020b). Mas também de fronteiras internas, que operam o bloqueio da circulação de fluxos vitais. Fronteiras raciais, nacionais, necropolíticas e epistêmicas, de arame farpado ou de concreto, elas definem as humanidades consideradas, regulam mobilidades e destituiçôes ontológicas os sujeitos que agem, de um lado; e os objetos sobre os quais se intervém, de outro: "seres de fronteira" (MBEMBE, 2017, p. 54). Codificada na linguagem da segurança, para além das fronteiras está o não-ser e a zona sem lei, os quais respaldam as práticas coloniais, com a intensificação do acesso violento aos corpos de sujeitos estigmatizados e aos seus territórios.

Entre quadros vivos e naturezas mortas, o ensaio de Mbembe atravessa fronteiras disciplinares, mais porosas e permeáveis do que se supóe. Ao longo dos seis capítulos do livro, articulam-se, em diálogo instável e intenso, o trabalho do luto e o trabalho da memória, de superação do trauma colonial e de remontagem, de destruição e de vontade de vida. Tensóes que se materializam também na língua e no verbo, em línguas duplas e repetiçóes inomináveis: na confusão babélica e na promessa do novo dia, cuja luz desvela, sob os escombros, a terra ainda banhada de sangue e de noite - um outro nome da morte.

Não é de estranhar que, no primeiro capítulo, "A partir do crânio de um morto: trajetórias de uma vida”, Mbembe articule as memórias da infância e da juventude, no Camaróes, às figurações noturnas e à morte, "[...] um modo de transformar em presença interior a destruição física daqueles que foram perdidos, que viraram pó." (MBEMBE, 2019a, p. 55). O gesto narrativo, que traz ao/à leitor/a as primeiras impressóes do momento pós-colonial, enreda-se ao questionamento de quem revisita as memórias, como viajante de passagem, para vasculhar arquivos de vida e de morte, "[...] no meio de uma multidão de signos táo efêmeros quanto eternos." (MBEMBE, 2019a, p. 38).

Retorna à terra de origem, não para reencontrar, ressignificar ou se reconciliar com qualquer coisa originária. $\mathrm{O}$ retorno, como em $O$ Diário de um retorno ao país natal, de Césaire, só se efetiva enquanto desvio. O inventário das memórias, entre destroços e cadáveres, exige nomear os fantasmas que transitam entre o velho e o novo mundo. Fantasmagorias de quem cresceu "[...] à sombra dessa região sem nome próprio porque, num certo sentido, o nome que ela recebeu é apenas o produto do espanto de um outro - um equívoco." (MBEMBE, 2019a, p. 34). E procura, no testemunho da memória silenciada, o testamento desaparecido no qual se inscreve uma dívida: nomear 
os mortos, cuja tarefa implica ainda "[...] dar à sepultura toda sua força subversiva” (MBEMBE, 2019a, p. 55).

Em "Declosão do mundo e escalada de humanidade", segundo capítulo do ensaio, a crítica direciona-se à perda do "teor incendiário" do conceito de descolonização, transformado em "[...] conceito de juristas e de historiadores" (MBEMBE, 2019a, p. 57). Se a descolonização é um processo cuja "[...] significação política essencial residiu na vontade ativa de comunidade”, orientada para "[...] uma nova lógica do sentido e da vida” (MBEMBE, 2019a, p. 10), como reduzi-la à mera "[...] transferência de poder da metrópole para as antigas posses coloniais no momento da independência?” (MBEMBE, 2019a, p. 57). Porque, enquanto categoria política, polêmica e cultural, a descolonização indica a insurgência voltada para declosão do mundo e para "[...] reconquista, pelos colonizados, da superfície, dos horizontes, das profundezas e das alturas de suas vidas." (MBEMBE, 2019a, p. 58) - força de autocriação.

Cabe ainda sublinhar, no contexto da modernidade tardia, a relevância de tematizar duas experiências negras, as quais apontam para os primórdios das independências coloniais: o caso do Haiti e da Libéria. Como gesto soberano de reivindicação por liberdade e autonomia, a independência e a abolição da escravidão não bastam, porém, para garantir um estado de autodomínio. Tanto no momento subsequente à Revoluçáo Haitiana quanto na descolonização planejada da Libéria, a emancipação parece vacilar diante da efetiva democracia e da discussão racial. Raça, cultura e nação tensionam-se, sem conciliação ou aprofundamento do debate acerca dos modos de habitar o Estado, das necessárias repactuaçóes político-epistêmicas e do engendramento de novas relaçôes de mutualidade.

É o que emerge também em "A sociedade francesa: proximidade sem reciprocidade". O título desse terceiro capítulo remete-nos à/ao outsider within (COLLINS, 2019a, p. 11), aqueles/as que são "quase de casa", mas "forasteiros/ as de dentro", invisibilizados/as. Porém, a figura do/a estrangeiro/a "fora do lugar” não indica apenas os sujeitos francófanos da diáspora em território francês. É a própria nação francesa, "ocupante sem lugar", que adquire os contornos do intimo estranho, cujo passado em comum com os ex-colonizados não significa, todavia, uma partilha conjunta, porque, de um lado, se a colonização é uma "[...] coprodução dos colonizadores e dos colonizados" (MBEMBE, 2019a, p. 12), de outro, a descolonização dos territórios por parte dos invasores europeus e, consequentemente, o que se entende por póscolonialismo, enseja uma série de paradoxos, na medida em que as antigas 
potências coloniais descolonizaram sem se autodescolonizar. Aqui, Mbembe procede a mais uma crítica ferrenha à sociedade francesa, orgulhosa de si e do seu passado "iluminado", mas que se recusa a responsabilizar-se pela violência da empresa colonial - concebida como atividade humanitária. Evidentemente, a hierarquização racial adquire um lugar central nesse discurso, que naturaliza relações de opressão sob os termos do "colonialismo desenvolvimentista".

"O longo inverno imperial francês", por sua vez, expóe os desdobramentos desse processo incompleto de autodescolonização. Reprimido o passado colonial e fixada à "boa consciência", sem qualquer autocrítica ou política reparatória, a França obsta, também no plano epistemológico e acadêmico, os caminhos abertos pelo pensamento pós-colonial. Nesse quarto capítulo do ensaio, Mbembe tematiza a incapacidade de escrita de uma história comum entre naçóes colonizadoras e naçóes independentes do continente africano, a partir de um passado compartilhado - compartilhado, mas cuja história obstaculiza qualquer possibilidade de constituição de uma comunidade efetiva, bem como de concatenação dos mundos, em um contexto de reforço de fronteiras, de separação e provincialização. Ao destacar "[...] o colonialismo e as doenças póstumas da memória” (MBEMBE, 2019a, p. 166), discute ainda a ambiguidade que pauta a política da memória pós-colonial, com relevo particular para a construção da memória republicana francesa, cuja coerência e unidade se fundamentam naquilo que ela exclui.

Em sua obstinada recusa, a França, afirma o autor camaronês, não pensa a pós-colônia. Paternalismo e racismo sedimentam-se em estruturas históricas de desigualdade, mascaradas pela civilidade e pelo humanismo universalista, que fizeram da África francófona uma "reserva de caça" francesa (MBEMBE, 2019a, p. 101). No jogo da submissão e da filantropia, a raça interpóe-se, uma vez mais, como ferramenta para manutenção do poder colonial.

Em "África: a cubata sem chaves", quinto capítulo do livro, a metáfora da casa fechada e sem abertura indica a clausura imposta ao continente africano, esquadrinhado e dividido arbitrariamente, na Conferência de Berlim (1884-1885). Surgidas formas inéditas de territorialidade, as topografias da violência são intensificadas pela implementação discricionária das faixas de fronteiras, cada vez mais militarizadas. As fronteiras redefinem relaçôes de rivalidade, de força e de alianças, de modo distinto, como, outrora, demarcavam espaços de encontros e de negociaçôes. Nesse sentido, a imposição de fronteiras geopolíticas entre as naçôes africanas, mas também no interior de cada país, estrutura os limites de controle dos Estados coloniais 
e multiplica o número de "[...] entidades territoriais com estatutos distintos e desiguais" (MBEMBE, 2019a, p. 181), com recorte étnico e racial. Isso resultaria tanto no sistema do apartheid quanto na atribuição de "[...] todo peso financeiro da reprodução das populaçóes negras sobre elas mesmas", circunscrevendo "[...] o fenômeno da pobreza a enclaves territoriais de conotação racial.” (MBEMBE, 2019a, p. 181).

Por fim, em "A circulação dos mundos: a experiência africana”, último capítulo do ensaio, é apresentado o desafio inconcluso da descolonização, a ser enfrentado, tal como exposto por Fanon, em Os condenados da terra: "[...] tratar por muitos anos ainda as feridas múltiplas e às vezes indeléveis deixadas em nossos povos pela derrota colonialista." (FANON, 2003, p. 239). Todavia, igualmente, de pensar esse mundo-africano-que-vem, irredutível às identidades fixas e a um único mundo. Como abertura em direção a práticas cosmopolíticas, afirmam-se a criação de novas relaçôes, possibilidades de viver e de ser: "[...] a potência do futuro inscrita no presente." (MBEMBE, 2019a, p. 245).

Com sua força desestabilizadora, o texto desafia tanto a ordem monológica ocidental quanto a modernização ensejada pelas elites africanas, haja vista que, no ensaio, o passado e o futuro se atam a experiências do presente, mas direcionadas a novas geografias da imaginaçáo política a serem forjadas. Pode-se afirmar, portanto, que Sair da grande noite é um livro estruturado a partir de cruzamentos imprevisíveis e fronteiras porosas, móveis, os quais se metamorfoseiam, abalados por sismos diversos, brados de protesto, fragmentos e memórias da (pós-)colônia.

O esforço de habitar vários mundos ao mesmo tempo, desde África, desdobra-se no vaivém reflexivo do autor, de idas e vindas entre o corpo e a escrita, história e memória, com vistas a articular um pensamento da circulação e da travessia e a escavar zonas de passagem, como espaços de respiro e de resistência à clausura ocidental. Pensamento-em-situação, em curso, metamórfico - pois em jogo está também a própria vida, a própria história e o próprio nome daqueles que, sem nome próprio e desapropriados de si e da terra, foram alçados a substantivos comuns de uma vida sem substância, bestializada.

$\mathrm{Na}$ parte final do livro, uma entrevista realizada com o cientista político, publicada no Télérama, em 2010, à ocasiáo do lançamento do ensaio, encerra suas reflexóes. Mbembe, uma vez mais, reitera como o 
racismo é o elemento central das políticas coloniais e o vínculo inextrincável entre descolonização e desracialização. A exigência da descolonização subjetiva é incontornável para a reconstituição da humanidade de sujeitos inferiorizados - tarefa, simultaneamente, política, epistemológica e estética.

Achille Mbembe oferece-nos, assim, um ensaio de extrema vitalidade, que se configura como reflexão sobre as relaçóes entre a memória, a raça e a nação. E, certamente, como provocação diante do muro narcísico que se ergueu ao redor da Europa, como barreira de um "[...] etnonacionalismo racializante" (MBEMBE, 2019a, p. 118). Em contraposição, apostase no movimento, na travessia e na "circulação dos mundos", tal como o afropolitismo enuncia. Esse paradigma, nas trilhas de Mbembe, redimensiona o movimento de constituição de um mundo comum, por vir, junto ao povo a ser criado na luta e por meio da luta.

Eis o apelo que ressoa nesse "sair da grande noite", voltado para um futuro que só pode emergir direcionado para a democracia que virá (MBEMBE, 2019a, p. 115), em diálogo com os fantasmas da (des)colonização, e que traz a exigência da implicação radical em relação à política da memória, à justiça e à reparação. Subversão flamejante, insurgência viva, urgente, que queima, por dentro, o próprio corpo do texto. Como promessa inacabada, móvel, latente. Com respiração de combate.

\section{REFERÊNCIAS}

CÉSAIRE, Aimé. Discurso sobre a negritude. Trad. Ana Maria Gini Madeira. Belo Horizonte: Nandyala, 2010.

COLLINS, Patricia Hill. Pensamento feminista negro: conhecimento, consciência e a política do empoderamento. Trad. Jamille Pinheiro Dias. Sáo Paulo: Boitempo, 2019.

ELA, Jean-Marc. Restituir a história às sociedades africanas: promover ciências sociais na África Negra. Luanda: Mulemba; Mangualde: Pedalgo, 2013. (Coleção Reler África).

FANON, Frantz. Les damnés de la terre. Paris: La découverte, 2003 [1961].

FANON, Frantz. Pele negra, máscaras brancas. Trad. Renato Silveira. Salvador: Editora UFBA, 2008.

MBEMBE, Achille. Políticas da inimizade. Trad. Marta Lança. Lisboa: Antígona, 2017. MBEMBE, Achille. Crítica da razáo negra. Trad. Sebastiáo Nascimento. São Paulo: n-1, 2018. 
MBEMBE, Achille. Sair da Grande Noite: ensaio sobre a África descolonizada. Trad. Fábio Ribeiro. Petrópolis, RJ: Vozes, 2019a.

MBEMBE, Achille. A ideia de um mundo sem fronteiras. Trad. Stephanie Borges. Revista Serrote, Instituto Moreira Salles, 2019b. s.p. Disponível em: https://www. revistaserrote.com.br/2019/05/a-ideia-de-um-mundo-sem-fronteiras-por-achillembembel. Acesso em: 5 jul. 2020.

MBEMBE, Achille. Brutalisme. Paris: La Découverte, 2020.

REIS, Diego dos Santos. O governo da emergência: Estado de exceção, guerra ao terror e colonialidade. Rio de Janeiro: Multifoco, 2020a.

REIS, Diego dos Santos. Politicas da Inimizade, de Achille Mbembe - Resenha. Cadernos de Ética e Filosofia Política, São Paulo, v. 2, n. 37, p. 252-256, 2020 b.

SHAKESPEARE, William. Hamlet. Trad. Anna Amélia de Queiroz Carneiro de Mendonça e Bárbara Heliodora. Rio de Janeiro: Nova Fronteira, 2015.

Recebido: 30/8/2020

Aceito: 20/01/2021 